\title{
Los niños rompen el silencio. Estudio exploratorio de conductas agresivas en la escuela costarricense
}

\section{Children break the silence. An exploratory study about aggressive behavior in Costa Rican schools}

\author{
Hannia Cabezas Pizarro \\ Catedrática, Escuela de Orientación y Educación Especial \\ Universidad de Costa Rica \\ Costa Rica \\ hanniac@gmail.com
}

Recibido: 21-IX-2010 • Aceptado 22-X-2010 • Corregido 17-V-2011

\begin{abstract}
Resumen: En esta investigación se pretende explorar el grado de violencia que existe entre los niños y niñas que cursan estudios en la educación primaria de las escuelas costarricenses. Para efectuar este trabajo, se seleccionó una muestra intencional de 916 estudiantes que cursaban los niveles de tercero a sexto grado, los cuales provenian de diversas zonas del país. Se halló que el $29 \%$ de los alumnos(as) ha sido victima de maltrato por parte de sus iguales de diferentes formas en una o más ocasiones. La información que aquí se analizó se obtuvo mediante una encuesta piloto adaptada para el estudio previamente administrada a grupos de adolescentes, la que contiene los criterios establecidos por Olweus (1998) para identificar el acoso escolar.
\end{abstract}

Palabras clave: Bullying, maltrato entre iguales, acoso escolar, víctimas, violencia escolar, matonismo, agresión en la escuela.

\section{Marco referencial}

Las relaciones en el aula son complejas. La elaboración del conocimiento, la formación en los valores y el desarrollo de los sentimientos se aprenden en la convivencia diaria entre el estudiante y el docente, el niño(a) y los compañeros(as), y el hijo(a) y los padres en el hogar. Esta es una labor conjunta en la que tanto padres, docentes y otras figuras autoridad deben asumir la responsabilidad.

El maltrato escolar es un fenómeno que se presenta a nivel mundial. Ha sido objeto de estudio en niños(as) y adolescentes con edades entre los 8 y 18 años. Su principal exponente lo definió como: "la situación de acoso e intimidación, en donde un alumno es agredido o se convierte en víctima cuando está expuesto, de forma 


\begin{abstract}
This investigation will try to explore the grade of violence that exists between boys and girls who study in Costa Rican primary schools. To carry out this investigation, a deliberate sample of $916 \mathrm{stu}$ dents were chosen who were in third and sixth grade, and who come from diverse parts of the country. It was found that $29 \%$ of the students have been victims of mistreatment caused by their peers in different forms in one or more occasions. The information that is analyzed in this investigation was obtained by means of a pilot survey, which was previously administered to groups of adolescents, but adapted for this study. This survey contains criteria established by Olweus (1998) to identify school harassment.
\end{abstract}

Key words: Bullying, mistreatment between peers, school harassment, victims, school violence, aggression in schools. repetida durante un tiempo, a acciones negativas que lleva a cabo otro alumno o varios de ellos" (Olweus, 1998 p. 25). Este maltrato puede tomar diferentes formas que van desde el maltrato físico, verbal, psicológico, social, hasta los abusos sexuales.

Tomando como base esta definición, se poseen tres criterios para identificar el acoso escolar. El primero se refiere a un comportamiento agresivo con la intención de causar daño físico y psicológico; el segundo se dirige a que las conductas agresivas se presentan de manera reiterada y se dan incluso más allá del horario escolar; el tercer criterio da a conocer que existe una relación interpersonal caracterizada por un desequilibrio de poder que lleva a la víctima a la impotencia, lo que la imposibilita a salir por sí sola de esa situación.

Al considerar este último punto, el defensor del pueblo español (2007) manifiesta que la victimización es un acto cobarde, ya que quienes lo llevan a cabo saben de antemano que saldrán ilesos de la situación puesto que la víctima se siente impotente para responder y no denuncia a los agresores.

Las experiencias que se dan en los diversos escenarios de las relaciones entre los niños(as) permean su mente y construyen sus hábitos y creencias. Es a partir de ellas que se elabora la personalidad y el autoestima; sin embargo, en muchas ocasiones las vivencias en el aula se convierten para muchos estudiantes en experiencias atemorizantes que, lejos de desarrollar el sentido de pertenencia y el placer por el estudio, desencadenan en verdaderos atropellos que lesionan severamente el amor propio al ser víctimas de sus propios compañeros(as) en el aula.

El fenómeno de la violencia escolar en Costa Rica es un hecho: 266 niños(as) de la muestra seleccionada manifestaron que han sido víctimas de agresión por parte de sus iguales de diversas formas, tanto físicas como emocionales. Las más usadas fueron los golpes, las patadas, 
empujones, insultos, amenazas y burlas que afectaron su moral y autoestima.

En este estudio se encontró que un $29 \%$ de niños y niñas son víctimas de sus compañeros(as), información que llama la atención por estar este porcentaje por encima de estudios realizados en el país con adolescentes (Cabezas y Monge 2007) en los cuales la prevalencia fue del 19.1\%. Asimismo, está sobre una muestra colombiana en la que Paredes, Álvarez, Lega y Vernon (2008) obtuvieron datos del 24.7\% de incidencia en su país.

Los índices encontrados en la muestra de escolares son comparables con países como Turquía que posee un 30\% (Alikasifoglu et ál., 2004) y Estados Unidos con un 24\% (Nansel et ál., 2001) en investigaciones realizadas con adolescentes.

\section{Objetivo del trabajo}

El objetivo de este estudio fue determinar la presencia del matonismo en niños y niñas que asistieran al primer ciclo del sistema educativo costarricense.

\section{Metodología}

Para realizar esta investigación, se seleccionó una muestra intencional de 916 estudiantes de ambos sexos con edades entre los 9 y 16 años, los cuales se encontraban cursando los niveles de tercero a cuarto grado en escuelas públicas y privadas del país. Al momento del estudio, los centros elegidos se ubicaban en Desamparados, Tibás, Paso Ancho, Barrio Cuba, Heredia, San José, San Pedro y Guadalupe de Cartago.

Se explicó a cada grupo en qué consistía el estudio y se motivó a los niños para que brindaran las respuestas. Se les indicó que debían resolver el cuestionario en forma individual y anónima, lo que facilitó la obtención de los datos.

\section{a) Instrumento}

Para recolectar la información, se elaboró una encuesta piloto con preguntas abiertas, semi-abiertas y cerradas con los criterios identificados a nivel mundial para detectar el fenómeno en estudio. Consistió en 8 preguntas abiertas y semi-abiertas dirigidas a las víctimas, e incluyó preguntas generales como datos sobre la edad, género y grado escolar. Las variables a medir fueron las siguientes: tipo de agresiones que sufren los estudiantes, frecuencia, lugar donde suceden los hechos, si en el momento de la agresión se encontraban solos(as) o acompañados(as), cuántas personas los agredieron, a quién recurrieron y si el problema continuó.

Para darle validez de construcción y contenido, se sometió a juicio de expertos. Se seleccionó a profesionales que laboraran en el campo de la Educación Especial, Orientación y Psicología y se incorporaron todas las sugerencias aportadas. El instrumento fue aplicado en investigaciones previas en Costa Rica (Cabezas, H., y Monge, 2007; Cabezas, 2007).

Los resultados que se obtuvieron se presentan convertidos en valores porcentuales en tablas y gráficos, agrupados según la ubicación del centro educativo y omitiéndose el nombre de la escuela donde se tomó la muestra.

\section{Análisis de los datos}

Los datos se analizaron porcentualmente y a continuación se presentan en tablas y gráficos. Se inicia con una distribución por zona geográfica de cada centro educativo, seguido de las variables que se pretenden medir en este estudio, las cuales son indicadores de la presencia de acoso escolar de acuerdo con investigaciones previas (Olweus, 1998). 


\section{Resultados y discusión}

De los datos obtenidos se desprende que 266 niños fueron víctimas de agresión por parte de sus compañeros, lo que equivale al $29 \%$ del grupo encuestado. En promedio, el $26 \%$ de los escolares de tercero a sexto fue víctima de algún tipo de maltrato.
En el siguiente gráfico se muestra el porcentaje de niños(as) que fueron víctimas de maltrato por parte de sus iguales, según las diferentes zonas donde se ubican las escuelas.

Como puede apreciarse en el gráfico 1 , las escuelas en donde mayor incidencia de maltrato entre iguales se presentó se

Gráfico 1

Porcentaje de niños (as) distribuidos por zona geográfica, que manifestaron haber sido víctimas de agresión

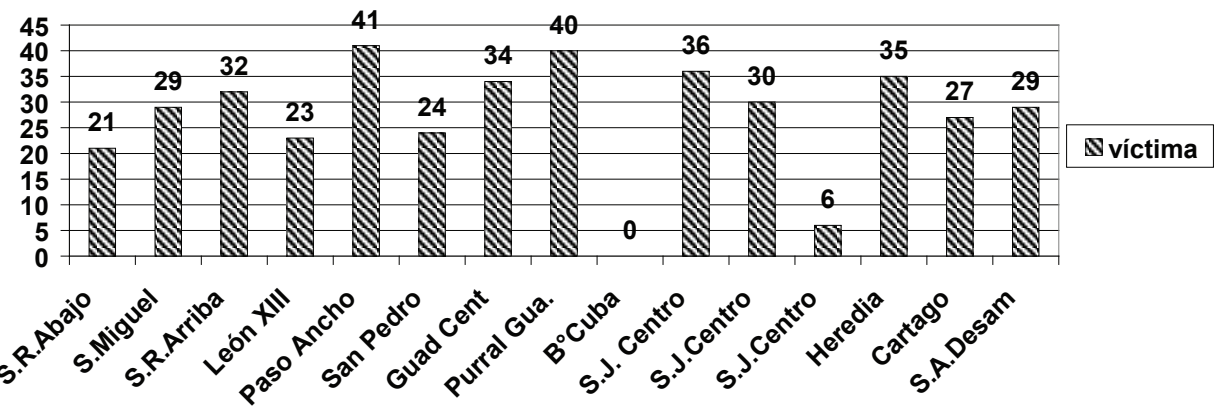

ubican en Purral de Guadalupe y en Paso Ancho, seguidas de San José Centro, Heredia, Desamparados, León XIII y Turrialba de Cartago. Algunas de estas zonas son consideradas conflictivas en el país; sin embargo, este no es un factor determinante para que se indique la presencia de la violencia en las aulas costarricenses porque el maltrato escolar se identificó en la mayoría de centros educativos encuestados. Los datos no mostraron diferencias significativas entre zona geográfica ni tampoco si el sistema educativo en donde se recibían las lecciones era público o privado.

En el centro educativo ubicado en Barrio Cuba, ninguno de los niños anotó haber sido víctima de agresión por parte de los compañeros(as). Sin embargo, ante la pregunta de cómo le agredieron o amenazaron, solo un estudiante manifestó que por medio de golpes o insultos. Este dato que no es significativo para indicar la presencia de acoso escolar porque parece ser un hecho aislado y ocasional.

Los niños imitan los patrones bajo los que son criados. Los métodos utilizados por sus padres o figuras de autoridad para educarlos son el castigo físico seguido del verbal. Estos se han determinado como un factor influyente para la presencia de conductas agresivas. En este sentido, Cerezo (2006, p.32) indica que: "El castigo o maltrato en cualquiera de sus diferentes formas, supone la forma más segura de conformar conductas agresivas en el futuro, incluso con mayor probabilidad que las experiencias frustrantes". 
Si un niño constantemente es agredido por parte de los padres, figuras de crianza o modelos de autoridad, va configurando mentalmente esquemas o patrones de respuestas agresivas, susceptibles de ser repetidas cuando se enfrente de nuevo a situaciones similares bajo las que fue maltratado.

El dato de $29 \%$ de niños(as) que reportan un tipo de agresión obtenido en la muestra costarricense es alarmante ya que el acoso escolar conlleva al aislamiento y a la poca interacción social. Los niños(as) se ven afectados en su evolución natural, incidiendo estas malas experiencias en el área cognitiva y en el progreso académico. Este indicador es comparable con el obtenido en estudios realizados en países como Estados Unidos y Noruega (Nansel et ál., 2001).

$\mathrm{Al}$ ser la escuela el sitio en donde se desarrollan habilidades sociales y el docente una figura de autoridad a imitar por parte de los educandos, los lineamientos que dicte y las técnicas que aplique se convierten en un factor determinante para el aprendizaje y la convivencia escolar.

En la tabla 1 se resume la información acerca de los conflictos los escolares encuestados.

Tabla 1

Formas más frecuentes de agresión

\begin{tabular}{lc}
\hline Tipo de maltrato & Porcentaje. \\
\hline Apodos & 37 \\
Golpes & 36 \\
Insultos & 23 \\
Empujones & 17 \\
Otros & 11.5 \\
Armas fuego & 3.4 \\
Amenaza & 3 \\
\hline
\end{tabular}

De estos datos se desprende que la forma más utilizada por los niños para resolver los conflictos fue mediante los golpes, los empujones, los insultos o haciendo mofa de características físicas de los compañeros(as). Pareciera que los estudiantes tienen poco control de la impulsividad y se arremete contra los iguales sin mediar palabras o intentar solucionar las diferencias. Llama la atención la presencia de armas de fuego en personas de tan corta edad.

Estos datos pueden compararse con estudio realizado con estudiantes de $6^{\circ}$ a $8^{\circ}$ año (Cabezas, 2007) y con la tipología identificada por Finkelhor y DziubaLeatherman (1994), quienes identificaron en primer lugar las victimizaciones generalizadas que con frecuencia sufren los niños(as) durante su desarrollo, dentro de las que citan el castigo físico por parte de los padres, el vandalismo y el robo; en segundo lugar nombran las agudas, menos frecuentes pero más graves, dentro de las que destacan la negligencia, el maltrato físico y el abuso sexual.

En el gráfico 2 se representan los porcentajes obtenidos relacionados con las formas de agresión.

Gráfico 2

Porcentajes de formas más frecuentes de agresión

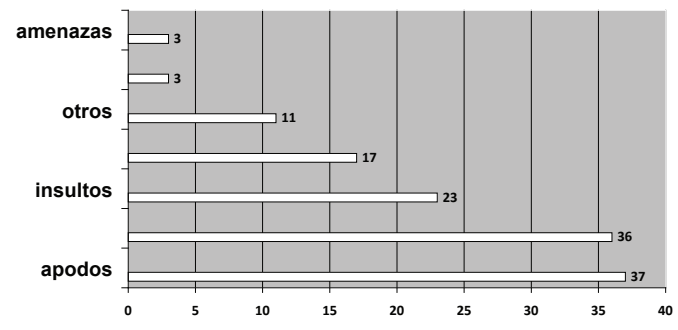




\section{Comentario}

Los porcentajes obtenidos indicaron que un número considerable de niños fue victimizado por sus compañeros por medio de golpes, empujones, insultos o apodos; actos que pueden generar sentimientos de inferioridad, bajo autoconcepto e incidir en el aprendizaje. Así mismo los niños pueden estar en riesgo social al afectarse su estado emocional y futuras reacciones conductuales.

Cerezo (2006) hace referencia a estudios previos que indican correlaciones muy altas entre el comportamiento de niños(as) segregados por sus compañeros y los descritos por niños(as) maltratados. En ambos grupos, los estudiantes reaccionaron ante las diversas circunstancias agresivamente como una forma habitual de interacción social.
Gallardo y Jiménez (1977) afirman que en los niños(as) víctimas de maltrato se generan estados de depresión y ansiedad cuando perciben que no son aceptados dentro del grupo de iguales. Un estudiante con depresión o trastorno de ansiedad como consecuencia de maltrato entre iguales probablemente tampoco tenga buen rendimiento escolar y en general posea menos herramientas que le permitan sobrevivir en el ambiente del aula, lo que podría desencadenar en la deserción del sistema educativo.

Al unir los criterios de este estudio bajo los que se tipifican el maltrato físico y emocional, se obtienen datos de $55 \%$ para el maltrato físico y $63 \%$ para el emocional. Los resultados se representan en la figura 3.

\section{Gráfico 3}

Porcentaje de maltrato físico y emocional

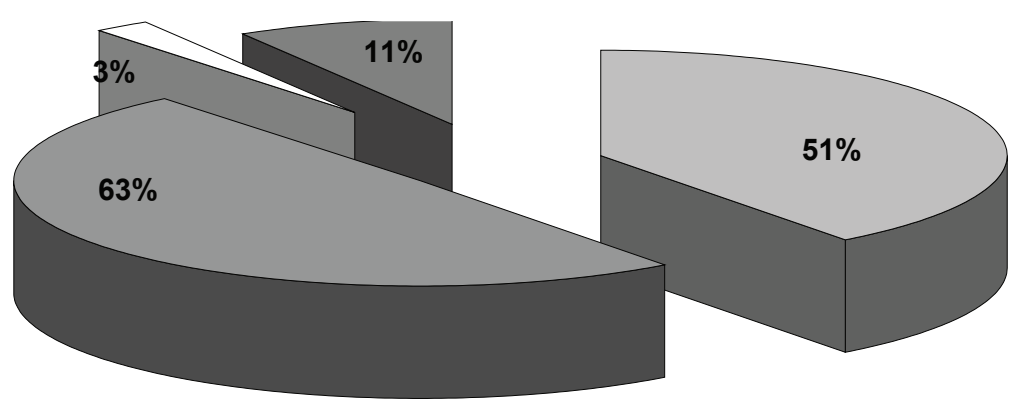

$\square$ físico $\square$ emocional $\square$ arma fuego $\square$ otro

\section{Comentario}

El maltrato emocional ha sido definido como: "la respuesta repetitiva e inapropiada que se ofrece al niño ante sus experiencias emocionales y las expresiones que las acompañan.” (Gómez de Terreros, 2006, p. 107)
Las marcas tangibles del maltrato emocional no se pueden evidenciar, pero la huella que deja es visible en el comportamiento a corto y a largo plazo. Esta es una de las formas más dañinas y destructivas de maltrato, porque si un niño constantemente es humillado, degradado, ridiculizado 
o criticado, se convierte en víctima de la inseguridad, pierde la confianza en sí mismo y se afecta su autoestima.

Se ha generalizado el uso del maltrato emocional por parte los adultos, el cual se lleva a cabo por medio de la indiferencia, rechazo u hostilidad, lo que afecta el desarrollo normal del niño; igualmente, la evidencia muestra que estos patrones de conducta están siendo repetidos por los niños y se están gestando como una forma de relación entre los estudiantes costarricenses provocando miedo, inseguridad humillación y desesperanza. Al respecto, (Schoenfeld, 2007) anota:

Ahora, sin embargo, volvían la tristeza, la depresión, el estado inicial. Cuando me faltaban pocos papeles por desechar, comencé a llorar otra vez. Dios mío, mi reserva de lágrimas era inagotable... Me eché a llorar desconsolado. En ese momento regresó a mí un pensamiento que creía desaparecido, que por mucho tiempo rondó mi cabeza y que aparentemente también estaba escondido. Pensé de nuevo en el suicidio (p.93).

El bullying se ha definido como: "La situación de acoso e intimidación, en donde un alumno es agredido o se convierte en víctima cuando está expuesto, de forma repetida durante un tiempo, a acciones negativas que lleva a cabo otro alumno o varios de ellos". (Olweus ,1998, p. 25)

De esta definición se desprende que el abuso escolar es reiterado y se lleva a cabo por una o más personas; condiciones que se encontraron presentes en la muestra costarricense, donde un $26 \%$ de los niños manifestó haber sido ser agredido a diario, un $20 \%$ una vez a la semana, un $18 \%$ una vez al mes y el $26 \%$ una vez al año. Los datos se representan en la figura 4 .

Gráfico 4

Frecuencia en que son agredidos los niños

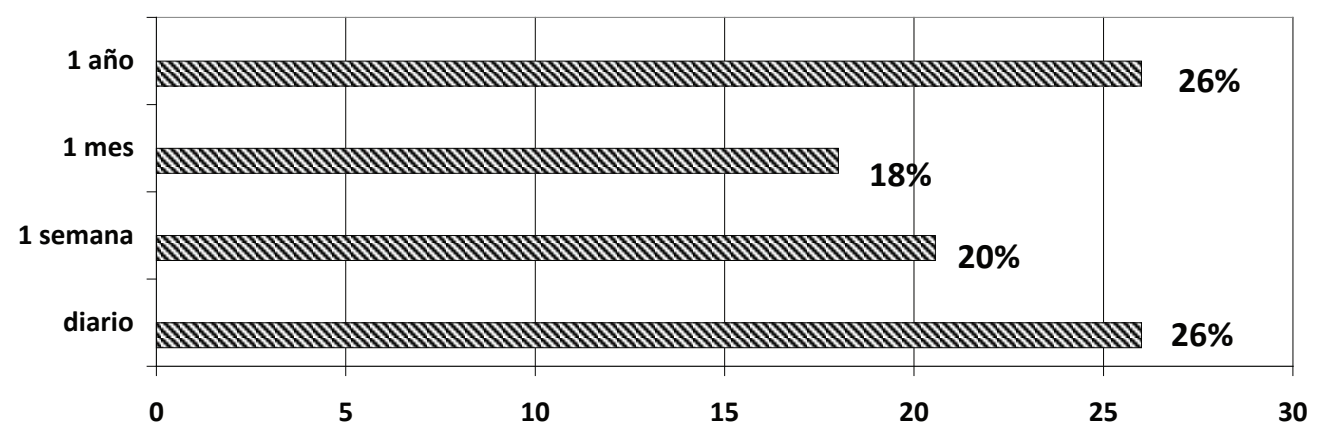

\section{Comentario}

Si un estudiante es maltratado por sus iguales por medio de golpes, patadas, insultos, burlas y chantaje en forma frecuente o una vez a la semana, probablemente las consecuencias de estos actos se harán sentir a corto o largo plazo presentándose en conductas como: inseguridad, dependencia, dificultades adaptativas y terminan por relacionarse los estudiantes agredidos con adultos y no con niños de su misma edad. Es por esto que deben implementarse programas urgentes en las escuelas que brinden herramientas a los docentes para prevenir el bullying y futuros comportamientos inadaptados, ya que las víctimas podrían ser parte de un grupo en alto riesgo social. Egeland et ál. comenta: "Se ha señalado que aquellos que fueron 
diagnosticados con trastornos de conducta antes de los diecisiete años, pueden mostrar, llegada la edad adulta, problemas de comportamiento anti social" (citado por García, 2006).

En esta investigación se encontró que un $51 \%$ de los niños que manifestaron haber sido víctimas por parte de sus compañeros(as) recibieron las agresiones por solo una persona, mientras que un $36 \%$ por varios compañeros. El 39\% de las veces los estudiantes se encontraban solos y un 59\% acompañados por otros compañeros o compañeras. (Ver gráficos 5 y 6 )

\section{Gráfico 5}

Número de personas que le agredieron

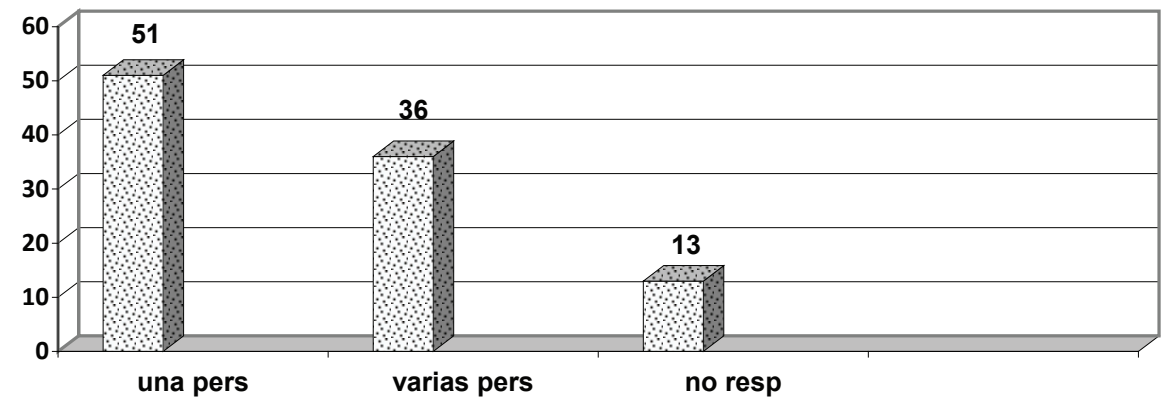

Gráfico 6

\section{Número de personas que le agredieron}

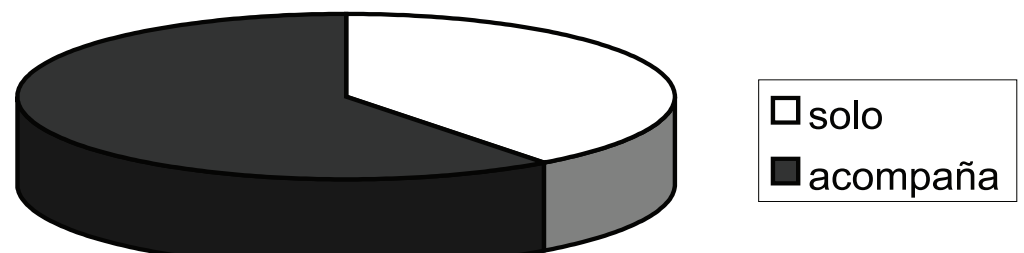

\section{Comentario}

El agresor diluye la responsabilidad de sus actos maltratando a las víctimas en presencia de otros niños(as) que observan los hechos sin intervenir y sin decir nada, convirtiéndose en cómplices silenciosos a pesar de no estar de acuerdo con la situación por temor a convertirse en víctimas futuras. Estos escenarios en donde otros niños(as) son observadores y no intervienen para defender a los compañeros generan más temor en las víctimas, además de vergüenza e impotencia y sensación de fracaso, y en el victimario se refuerza el matonismo al verse aprobada la conducta por los espectadores.

Se supone que un medio como la escuela es seguro, pero debido al contexto del bullying les proveyó más bien experiencias negativas 
a los niños(as) que participaron de este estudio. En este sentido, el centro educativo podría convertirse en un sitio hostil y amenazador en donde los estudiantes no podrían actuar con éxito ni fortalecer sus creencias para ser aceptados dentro del grupo social en el que se desenvuelven. De ser así, la educación como función social estaría fallando, porque no estaría brindando un ambiente seguro para el desarrollo y crecimiento de los alumnos.

La escuela ha de ser capaz de dirigir y transformar el crecimiento humano, pero si el ambiente es hostil, las actitudes y valores no podrán modelarse adecuadamente, ni tampoco ella podrá hacer de los educandos partícipes de la acción en el aula de manera que aprendan de los éxitos y fracasos.

Se encontró que los sitios en donde más se victimiza a los niños en los diferentes centros educativos son: en el salón de clases un $32 \%$, en los corredores el $27 \%$, en el patio el $17 \%$, en baño el $8 \%$ y cerca de la casa el $23 \%$. Los porcentajes que se representan en el gráfico 7 .

Frecuencia de agresiones según el lugar donde se presentan

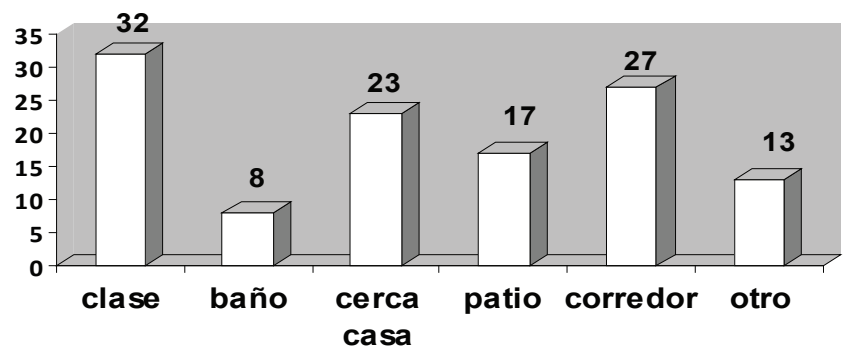

$\square$ porcentaje

\section{Comentario}

El acoso a los niños(as) se presentó principalmente fuera del aula (46\%), en sitios como el patio, corredor, y baño, probablemente porque en estos lugares se mantiene menor vigilancia por parte de los adultos. Por lo tanto, deberían dictarse políticas escolares que permitan establecer responsabilidades ante la presencia de estos actos y estrategias que lleven al juego colectivo en los recreos. Además, deben diseñarse áreas seguras en la planta física de la escuela, que sean supervisadas por adultos. Mazzone y Querciolo proponen que: "El trabajo en el ambiente físico del patio de recreo incluye su estructuración o rediseño para proveerles a los alumnos más oportunidades recreativas durante el recreo y la hora de almuerzo, y para reducir el aburrimiento y el acoso." (2009, P. 34)

El control del aula debe estar a cargo del docente, quien es el llamado a poner límites, enseñar, actuar y llevar al estudiante a participar de la experiencia en el salón de clase aplicando las medidas necesarias para alcanzar los fines propuestos.

$\mathrm{Al}$ observar el maestro conductas dentro del salón de clases como empujones, patadas, arrebato de pertenencias, robos, burlas, chantaje, bromas pasadas de tono, entre otras, podría predecir el resultado de este actuar y anticiparse a los hechos implementando planes de acción que mejoren la convivencia escolar. Para ello se requiere ser parte 
de la acción y no convertirse en un ente pasivo que ignore las situaciones, ya que un porcentaje alto de niños(as) víctimas de agresión en el aula que participaron de este estudio recurrieron a ellos pero casi no se hizo nada para ayudarlos. En el cuadro y en los gráficos siguientes se anotan los porcentajes relacionados con las personas a quienes recurren los estudiantes cuando son víctimas de agresión.

Gráfico 8

Personas a quienes recurren los estudiantes cuando son victimizados

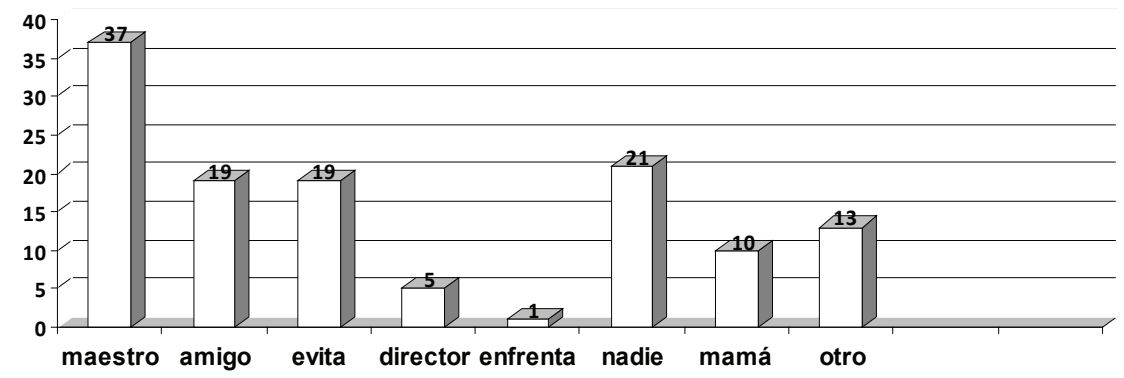

\section{Comentario}

Si bien es cierto que un porcentaje alto de niños(as) (37\%) recurren al maestro de aula en busca de protección y ayuda, se encontró que un $21 \%$ no dicen nada sobre las agresiones por temor a ser victimizados con mayor violencia, convirtiéndose en presa fácil de sus compañeros (as), quienes se aprovechan de la vulnerabilidad y debilidad de sus iguales y se escudan en la impunidad para seguirlos agrediendo. Muy pocos niños tienen las herramientas necesarias para defenderse, de allí que solo un 1\% se atrevió a enfrentar a los victimarios.

A pesar de buscar ayuda o recurrir a figuras de autoridad, las amenazas continuaron para un $24 \%$ de los estudiantes, mientras que un $56 \%$ manifiestan que cesaron (ver gráfico 9).

Gráfico 9

Continuaron y se detuvieron las amenazas

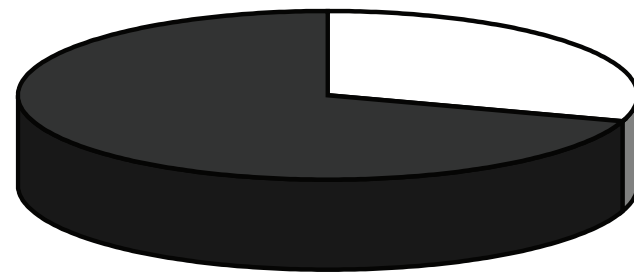

\section{$\square$ continuan \\ no continua}




\section{Comentario}

La situación se tornó insostenible para un $24 \%$ de los niños que denunciaron la situación, y como represalia los compañeros(as) los molestaron más y los agredieron con mayor intensidad. En la siguiente tabla se anota lo que manifestaron los estudiantes en relación con lo que sucedió una vez denunciado el hecho.

Tabla 2

¿Qué sucedió luego de hacer la denuncia?

\begin{tabular}{lc}
\hline \multicolumn{1}{c}{ ¿Qué cosa pasó? } & Porcentaje \\
\hline No puedo contar & $3 \%$ \\
$\begin{array}{l}\text { Se hizo más grande el } \\
\text { problema }\end{array}$ & $7 \%$ \\
Me amenazaron más & $10 \%$ \\
Me insultaron más fuerte & $2 \%$ \\
$\begin{array}{l}\text { Me golpearon con más } \\
\text { fuerza }\end{array}$ & $17 \%$ \\
Me molestaron más & $8 \%$ \\
Me enviaron a mí una & $1 \%$ \\
boleta & \\
Me quisieron ahorcar & $1 \%$ \\
\hline
\end{tabular}

\section{Comentario}

Como puede apreciarse, las denuncias de muchos niños no fueron atendidas adecuadamente y el maltrato continuó con mayor intensidad. Pocos maestros implementan medidas correctivas en el aula. Pareciera que para tomar acciones debería presentarse un daño físico evidente. Generalmente se ignora uno de los mayores maltratos de que son objeto los niños como lo es el emocional que, por ser invisible, no se interviene oportunamente. Al respecto Ortega y Mazonne indican que: "el simple abandono de la función protectora y formativa que deben tener los docentes hacia sus alumnos y alumnas, así como el posible trato indigno, falto de respeto o agresivo que pueden llegar a tener estos hacia aquellos, son formas de violencia que abren una brecha en el camino de la fractura social" (2009, p. X).

Conforme se intensifican las agresiones hacia las víctimas, queda en evidencia la intencionalidad del agresor, el deseo de provocar más daño y la continuidad en el tiempo del maltrato. Además se nota la fragilidad de las víctimas al no encontrar protección en las figuras de autoridad.

\section{Conclusiones}

El acoso escolar en las aulas costarricenses es una realidad que debe abordarse en forma comprensiva, integrándose tanto aspectos sociológicos, psicológicos y educativos como políticos para poder abordarlo y detenerlo.

Se requiere en el país de programas preventivos que apliquen los docentes desde edades tempranas con los niños(as) que brinden conocimientos acerca del maltrato escolar y cómo detenerlo, además de incluir como eje transversal el tema en los programas formativos para los docentes.

La escuela no debe abocar los esfuerzos solo a identificar la violencia en el aula, sino al dar soluciones a esta problemática que va en aumento y que tanto daño está causando a la población escolar costarricense.

Es importante establecer la diferencia entre lo siguiente: ¿qué es el acoso escolar y qué no lo es? No califican como maltrato escolar todos los actos de violencia que se presentan desde diferentes escenarios y publicitados a través de los medios de información colectiva como la violencia en los estadios, manifestaciones callejeras, presentaciones públicas, conciertos o actos vandálicos llevados a cabo por estudiantes.

El bullying es un fenómeno estudiado sistemáticamente desde 1998 (Olweus), en el cual debe haber un comportamiento repetitivo y agresivo con la intención de causar daño. Hay un agresor quien 
ejerce en forma constante el poder, lo que le permite autoafirmarse, y una víctima, que difícilmente logra salir por sí sola de la situación. En los agresores se presenta una motivación intrínseca de reafirmar su poderío ante los compañeros de aula. Al respecto (Menesini, 2009) refiere:

La motivación del acoso escolar no es, entonces, la de reaccionar de modo violento a una situación de provocación o la de obtener ventajas materiales mediante un ataque directo a un compañero, la motivación última es de tipo relacional y es la de afirmar el poder de uno sobre el otro en el ámbito de su propia red social de referencia (p.4).

Debe prestarse especial atención a los niños(as) agresores y víctimas del aula, porque podrían generalizar conductas que vayan más allá del escenario escolar a otros ambientes, y otras edades. Por lo tanto, los programas preventivos deben iniciarse desde preescolar y primaria llevando al desarrollo de habilidades sociales, autoestima, formación en los valores, actitudes, comportamientos antisociales, entre otros que prevengan esta problemática en la población costarricense.

Si el fin de la educación supone "una actividad ordenada, en la cual el orden consiste en la progresiva terminación de un proceso" (Dewey, 1963: p. 106), el fin conlleva a la previsión, y si las condiciones dentro aula no permiten que el estudiante se desarrolle integralmente y en forma armónica, la educación le está fallando.

\section{Referencias bibliográficas}

Alikasifoglu, M., Erginoz, E., Erca, O. Uysal, O., Kaymak, D.A \& Ilter, O. (2004) Violent behavior among Turkish high school students and correlates of physical fightind. European Journal of Public Health, 14(2), 173-177.

Cabezas, H. \& Monge, I. (2007). Maltrato entre Iguales en la escuela Costarricense. Revista Educación, 31 (1), 135-144.
Cabezas, H. (2007) Detección de conductas agresivas "Bullying" en escolares de sexto a octavo año, en una muestra costarricense. Revista Educación 31(1). 123-133

Cerezo, F. (2006). La violencia en las aulas. Ediciones Pirámide (grupo Anaya S.A). Madrid, España.

Dewey, J. (1953). Democracia y Educación. Editorial Losada, S.A. Argentina.

España. Defensor del Pueblo. (2007). Violencia escolar: el maltrato entre iguales en la Educación Secundaria Obligatoria 1999-2006. Madrid: Defensor del Pueblo

Finkelhor D. \& Diuba-Leatherman, J. (1994) Victimization of children. American Psychologist. (3) 49, 173-183

Gallardo, J.A. y Jiménez, M. (1977). Efectos del maltrato y del status sociométrico sobre la adaptación social y afecto infantil. Psicothema, 9 (1), 119- 131

García, M.E. Consecuencias del maltrato físico infantil sobre los problemas de conducta: mediadores y moderadores. Intelligo, 1(1), 49-61, 2006

Gómez de Terreros, M.. Maltrato psicológico. Cuadernos médico forense [online]. 2006, n.43-44, pp. 103-116. ISSN 1135-7606.

Mazzone, F. Querciolo, M. (2009) (compiladores) Educación en contextos de violencia y Violencia en contextos educativos. Bianiamini GroupRoma Italia.

Menesini, E., (2009) en: Educación en contextos de violencia y Violencia en contextos educativos. Bianiamini Group- Roma Italia.

Nansel, T.R., Overpeck, M.D., Pilla, R.S., Ruan, W.J., Simons-Morton, B., \& Scheidt, P.C. (2001) Bullyings behaviors among US youth: Prevalence and association with psychological adjustment. Journal of the American Medical Association, 285, 2094-2100

Olweus, D. (1998). Bullying at school: What we know and what we can do. 
(Edición en español: Conductas de acoso y amenaza entre escolares). Madrid: Ediciones Morata.

Paredes, M.T., Álvarez, M.C., Lega., L.I. \& Vernon, A. (2008). Estudio exploratorio sobre el fenómeno del "bullying" en la ciudad de Cali, Colombia. Revista Latino Americana de Ciencias Sociales en Niñez y Juventud, 6 (1), 197-212.

Schoenfeld, J. (2007) El día que no existi. Editorial Perro Azul. San José Costa Rica. 